\title{
Childhood Diabetes Mellitus and the 'Double Burden of Malnutrition': An Emerging Public Health Challenge in Developing Countries
}

Samuel N Uwaezuoke*

College of Medicine, University of Nigeria Nsukka and Honorary Consultant Pediatrician, University of Nigeria Teaching Hospital Enugu, Nigeria

${ }^{*}$ Corresponding author: Dr. SN Uwaezuoke, Department of Pediatrics, UNTH Ituku-Ozalla 400001 Enugu, Nigeria, Tel: 23-48033248108; E-mail: snuwaezuoke@yahoo.com

Rec Date: August 15, 2015; Acc Date: August 26, 2015; Pub Date: August 31, 2015

Copyright: (C) 2015, Uwaezuoke SN. This is an open-access article distributed under the terms of the Creative Commons Attribution License, which permits unrestricted use, distribution, and reproduction in any medium, provided the original author and source are credited.

\begin{abstract}
The 'double burden of malnutrition' refers to the simultaneous existence of both undernutrition and overnutrition in the same population across the life course. Diabetes mellitus (DM) - a major non-communicable disease - has been linked to both chronic undernutrition and obesity; the latter is now assuming prominence in developing countries. The present review aims to highlight the global burden of this non-communicable disease in children and its relationship with the 'double burden of malnutrition'. Type 2 DM has rapidly evolved from a disease of the Western world to a global disease; from a disease of affluence to a disease that now afflicts the poor; and from an adult-onset disease to a disease that is gaining prominence in the pediatric population. Estimates from the International Diabetes Federation show that diabetes affects at least 285 million people worldwide out of which two-thirds occur in developing (low-to middle-income) countries. The global epicenter of diabetes epidemic is located in China and India as Asia has undergone rapid economic development, urbanization and transitions in nutritional status. Overweight and obesity are propelling the worldwide diabetes epidemic. Central obesity is correlated with both insulin resistance and type 2 DM. Moreover, the scourge of chronic undernutrition among children in tropical developing countries may predispose them to malnutrition-modulated diabetes mellitus (MMDM) later in life. Children in these regions are thus faced with a health-related dilemma. There is an urgent need to develop a comprehensive prevention program targeted at reducing diabetes risk and promoting proper nutrition among children in these countries.
\end{abstract}

Keywords: Undernutrition; Overnutrition; Diabetes mellitus; Children; Developing countries

\section{Introduction}

The double burden of malnutrition (DBM) refers to the simultaneous existence of both under nutrition and over nutrition in the same population across the life course [1]. The repercussions of DBM are huge; early life undernutrition is an underlying cause associated with about a third of early childhood mortality. Later in the life course, diet and nutrition, and especially obesity are important fundamental causes of many non-communicable diseases such as hypertension, diabetes mellitus, cancer, stroke and ischemic heart disease [1]. The extremes of malnutrition therefore constitute a serious health challenge for children in tropical developing countries. For instance, the incidence of obesity is rising because of the phenomenon of 'Nutrition transition' [2], and other obesogenic factors like rapid urbanization and sedentary lifestyle [3].

Diabetes mellitus (DM) - a major non-communicable disease - has been linked to both chronic under nutrition [4,5] and obesity [3], although its relationship with chronic under nutrition has remained a subject of debate [6]. Previously, DM in children was essentially insulin-dependent (IDDM) or type $1 \mathrm{DM}$, but non-insulin dependent (NIDDM) or type $2 \mathrm{DM}$ is now becoming more common in young adults, teens and children; obesity is the major type 2 diabetes risk. Remarkably, the number of children with type 2 diabetes caused by obesity is increasing worldwide. On the other hand, chronic under nutrition has long been recognized as a cause of persistent insulin deficiency and glucose intolerance [4], and insulin resistance [5]. Thus, the World Health Organization (WHO) subsequently incorporated malnutrition-related diabetes mellitus (MRDM) as a category in the classification of diabetes [7], although it was deprecated in a revised classification of diabetes in 1999 which placed tropical chronic pancreatitis or fibrocalculous pancreatic diabetes (FCPD) as one of the causes of secondary diabetes.

The present review aims to highlight the global burden of this noncommunicable disease in children and its relationship with the 'double burden of malnutrition'. The literature search strategy involved a retrieval of relevant articles from Google and PubMed database using appropriate search terms.

\section{Diabetes Mellitus: A Snap-shot of the Global Picture}

Type $2 \mathrm{DM}$ has rapidly evolved from a disease of the Western world to a global disease; from a disease of affluence to a disease that now afflicts the poor; and from an adult-onset disease to a disease that is gaining prominence in the pediatric population [3]. Estimates from the International Diabetes Federation show that diabetes affects at least 285 million people worldwide out of which two-thirds occur in developing (low-to middle-income) countries [8]. Asia alone accounts for $60 \%$ of the world's diabetic population [3]. For instance, the global epicenter of diabetes epidemic is located in China and India as Asia has undergone rapid economic development, urbanization and transitions in nutritional status [9]. Interestingly, Asian populations develop diabetes at younger ages, at lower degrees of obesity and at much higher rates given the same amount of weight gain when compared with Western populations [9]. In the North America, type 2 DM now accounts for about $15 \%$ to $45 \%$ of all newly diagnosed cases 
of diabetes in children and teenagers [10,11]. Type $2 \mathrm{DM}$ has also been reported in children in Asian-Pacific countries such as Japan [12], India [13] and Australia [14], as well as in the United Kingdom [15]. Although type $1 \mathrm{DM}$ remains the major form of the disease in children worldwide, it is likely that type $2 \mathrm{DM}$ will be the predominant form within a decade in many ethnic groups [16]. For instance, among children in Japan, type $2 \mathrm{DM}$ is already more common than type 1 and accounts for $80 \%$ of childhood diabetes [12]. This decline in the age of onset of type $2 \mathrm{DM}$ is an important factor influencing the future burden of the disease [16]. Notably, the worldwide burden of the disease is rising significantly with most of the increase documented in the last two decades [17]. In 2003, the global prevalence of diabetes was estimated at $5.1 \%$ among people in the age bracket of 20 to 79 years and by 2025 , the prevalence is projected to be $6.3 \%$, a $24 \%$ increase compared with 2003 [18]. In the developing regions, the prevalence was highest in Europe and Central Asia and lowest in Sub-Saharan Africa. Nevertheless, the largest increase in prevalence by the end of the decade is expected to be in East Asia and the Pacific, and smallest in the Sub-Saharan Africa [18]. Some of the variations may mirror the disparities in the level of urbanization of the diverse populations. The global burden of diabetes as reflected in the mortality, disabilityadjusted life years (DALYs) and direct medical costs attributable to the disease by regions is shown in Table 1 .

\begin{tabular}{|c|c|c|c|c|c|c|c|c|}
\hline \multirow[t]{2}{*}{ Region } & \multicolumn{2}{|c|}{ Number of people (thousands) } & \multicolumn{2}{|c|}{ Prevalence (percent) } & \multicolumn{2}{|c|}{$\begin{array}{l}\text { Direct medical costs, } 2003 \text { (US\$ } \\
\text { million) }\end{array}$} & \multirow[t]{2}{*}{$\begin{array}{l}\begin{array}{l}\text { Deaths, } \\
\text { (thousands) }\end{array} \\
2001 \\
\end{array}$} & \multirow[t]{2}{*}{$\begin{array}{l}\text { Disability-adjusted } \\
\text { life years, } 2001 \\
\text { (thousands) }\end{array}$} \\
\hline & 2003 & 2025 & 2003 & 2025 & Low estimate & High estimate & & \\
\hline $\begin{array}{l}\text { Developing } \\
\text { countries }\end{array}$ & 140,849 & 264,405 & 4.5 & 5.9 & 12,304 & 23,127 & 757 & 15,804 \\
\hline $\begin{array}{l}\text { East Asia and the } \\
\text { Pacific }\end{array}$ & 31,363 & 60,762 & 2.6 & 3.9 & 1,368 & 2,656 & 234 & 4,930 \\
\hline $\begin{array}{l}\text { Europe and Central } \\
\text { Asia }\end{array}$ & 25,764 & 33,141 & 7.6 & 9 & 2,884 & 5,336 & 51 & 1,375 \\
\hline $\begin{array}{l}\text { Latin America and } \\
\text { the Caribbean }\end{array}$ & 19,026 & 36,064 & 6 & 7.8 & 4,592 & 8,676 & 163 & 2,775 \\
\hline $\begin{array}{l}\text { Middle East and } \\
\text { North Africa }\end{array}$ & 10,792 & 23,391 & 6.4 & 7.9 & 2,347 & 4,340 & 31 & 843 \\
\hline South Asia & 46,309 & 94,848 & 5.9 & 7.7 & 840 & 1,589 & 196 & 4,433 \\
\hline Sub-Saharan Africa & 7,595 & 16,199 & 2.4 & 2.8 & 273 & 530 & 82 & 1,448 \\
\hline Developed countries & 53,337 & 68,345 & 7.8 & 9.2 & 116,365 & 217,760 & 202 & 4,192 \\
\hline World & 194,186 & 332,750 & 5.1 & 6.3 & 128,669 & 240,887 & 959 & 19,996 \\
\hline
\end{tabular}

Table 1: Estimated Numbers of People Age 20 to 79 with Diabetes, Mortality, DALYs, and Direct Medical Costs Attributable to Diabetes, by Regions

\section{Obesity and Type 2 Diabetes Mellitus: The Nexus}

Overweight and obesity are propelling the worldwide diabetes epidemic [3]. For instance, in the United States, the prevalence of obesity in children and teenagers has closely paralleled the rise in the prevalence of type $2 \mathrm{DM}$ in this age group [19]. This trend shows that the links between obesity and type 2 DM are firmly established. First, for type 2 disease, being overweight or obese (Body mass index of $>$ 30 ) is a risk factor. Second, obesity leads to a metabolic condition'prediabetes' - which almost always develops into type $2 \mathrm{DM}$. According to the American Diabetes Association (ADA), 'pre-diabetes' is defined as a metabolic clinical condition which can predispose the affected subject to future development of diabetes [20]. Pre-diabetes involves two conditions namely impaired fasting glucose (IFG) and/or impaired glucose tolerance (IGT). Based on biochemical and laboratory parameters and in line with ADA guidelines [20], IFG is defined as a fasting plasma glucose level ranging from $100 \mathrm{mg} / \mathrm{dL}(5.6 \mathrm{mmol} / \mathrm{L})$ to $125 \mathrm{mg} / \mathrm{dL}(6.9 \mathrm{mmol} / \mathrm{L})$ while IGT is a condition characterized by 2 hour value of plasma glucose in the oral glucose tolerance test (OGTT) ranging from $140 \mathrm{mg} / \mathrm{dL}(7.8 \mathrm{mmol} / \mathrm{L})$ to $199 \mathrm{mg} / \mathrm{dL}(11.0 \mathrm{mmol} / \mathrm{L})$. In addition, a glycated hemoglobin (HbA1C) plasma level ranging from $5.7 \%$ to $6.4 \%$ is further considered as a pre-diabetic condition [20]. A recent extensive review has underscored the complex relationship between pre-diabetes, family history of diabetes and onset of cardiovascular diseases [21]. Interestingly, several studies have established a possible association between pre-diabetes and increased cardiovascular risk profile of subjects [22-25]. Furthermore, family history of diabetes mellitus is not only related to a pure increase in metabolic changes predisposing to the onset of overt diabetes but it seems to overcome the endocrinological alterations and to provoke early lesions even in the vascular walls [21]. Thus, family history of diabetes increases cardiovascular risk profile of subjects. Although this is not supported by strong scientific evidence, many observational studies have revealed its relationship with increased cardiovascular risk [21]. For instance, several workers have confirmed significant endothelial dysfunction in subjects with parental history of type $2 \mathrm{DM}$ [26-29], although another study has reported a contrasting finding [30]. Nevertheless, an association between carotid intima-media thickness (CIMT) and risk factors for atherosclerosis has been documented by some investigators [31]; underscoring the role of family history of type $2 \mathrm{DM}$ on development of cardiovascular risk. On the other hand, the role of diet in slowing the cardiovascular risk has 
recently become an area of focus [32]. Dyslipidemia is known to hasten the atherosclerotic process, and is one of the major risk factors for cardiovascular disease in DM. The lipid alterations associated with DM are attributed to increased free fatty acid flux secondary to insulin resistance. Recently, the use of nutraceuticals (food or food components which provide medical benefits including prevention and/or treatment of a disease) as well as functional foods (any food or food ingredients which may provide health benefit beyond the traditional nutrients it contains) have been reported to reduce the overall cardiovascular risk induced by dyslipidemia by acting parallel or as adjuvants to statins [32]. Similarly, a recent review has revealed that dietary omega-3 polyunsaturated fatty acids could improve endothelial function and structure early in life [33]. Given that endothelial dysfunction is a well-known early marker of atherosclerosis, its improvement early in life will definitely reduce the cardiovascular risk profile later in life [33].

The transition from obesity to diabetes is actualized by a progressive defect in insulin secretion coupled with a progressive increase in insulin resistance [34]. An increase in overall adiposity, especially of visceral and ectopic fat depots, is specifically associated with insulin resistance. Several studies have indeed established a link between insulin resistance and truncal obesity (visceral and central abdominal fat) [35-37]. Central obesity is correlated with both insulin resistance and type $2 \mathrm{DM}$ [38], and is now generally believed to be the fat depot that conveys the biggest health risk $[39,40]$.

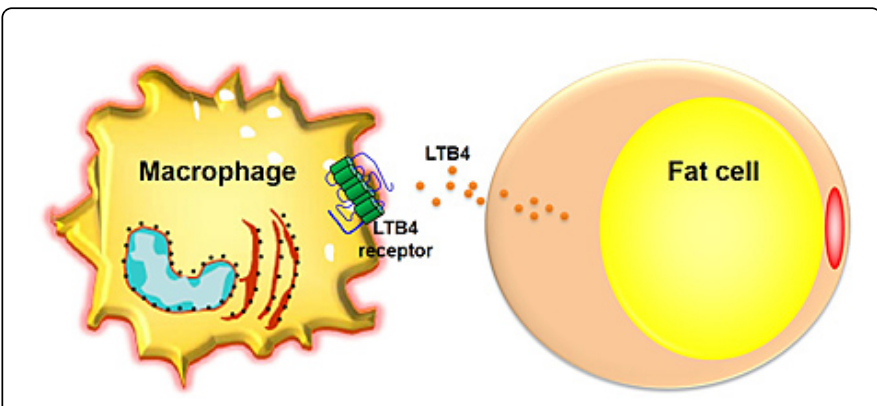

Figure 1: Extra fat cell triggers inflammation by releasing LTB4 which binds to receptors on nearby macrophages

Several theories have also evolved to explain the molecular pathway by which obesity leads to type $2 \mathrm{DM}$. For example, the medical literature is replete with the evidence-based role of serum resistin levels in this nexus between obesity and type 2 DM [41-45]. Increased obesity has been found to elevate serum resistin levels $[41,42]$, which in turn directly correlate with insulin resistance [43]. Furthermore, other workers have confirmed a direct correlation between resistin levels and type 2 DM [43-45]. However, recent findings indicate that the concept of 'silent inflammation' is the cause of insulin resistance. Increased production of arachidonic acids (AA) by fat cells which are metabolized to pro-inflammatory eicosanoids leads to formation of new inflammatory mediators (tumor necrosis factor [TNF], interleukin 6 [IL-6]). Central obesity is thought to increase the tendency of fat cells to release these eicosanoids which contribute to insulin resistance- a major step in the development of diabetes. A more recent pioneer research by Olefsky and co-workers [46] specifically identified a chemotactic eicosanoid- LTB4 as an attractive molecular link between obesity and type $2 \mathrm{DM}$. In obesity, extra fat cells trigger inflammation by releasing LTB4, which binds to receptors on nearby macrophages and activate them with the resultant effects of 'silent inflammation' and subsequent insulin resistance (Figure 1) [46].

\section{Chronic Undernutrition and Diabetes: The 'Controversial' Link}

Malnutrition- particularly under nutrition- has remained a major health challenge in children in low-income developing countries. Over $35 \%$ of under-five children in sub-Saharan Africa exhibit physical signs of malnutrition [47]. In retrospect, the relationship between chronic undernutrition and diabetes was brought to the fore following the report that protein- energy malnutrition (PEM) causes persistent insulin deficiency, glucose intolerance and insulin resistance [4,5]. The condition is characterized by chronic pancreatitis and was first described in Indonesia in 1959 [48], but was subsequently reported in sub-Saharan Africa [49-51], and South-east Asia [52,53]. Despite its initial classification by the World Health Organization as malnutritionrelated diabetes mellitus (MRDM) in 1985 [7], the role of PEM in its pathogenesis remains controversial. One author [54] suggests that glucose intolerance in PEM is associated with structural changes in the beta cell, and is irreversible despite sustained nutritional rehabilitation. Chronic undernutrition over a life time may thus be an important determinant of diabetes either by progressive impairment of beta cell function or increased susceptibility to other genetic and environmental diabetogenic influences [54]. MRDM has now been replaced with a new nomenclature: malnutrition-modulated diabetes mellitus (MMDM). MMDM can be subdivided into protein-deficient diabetes mellitus (PDDM) and fibrocalculus pancreatic diabetes (FCPD). FCPD- an uncommon form in West Africa but prevalent in other tropical populations- was considered a separate form of the disease in the revised WHO classification. While FCPD pancreatitis manifests itself in pancreatic duct calculi, PDDM is related to the presence of ketosis-resistant hyperglycemia [55]. MMDM patients are characteristically young at onset with low body mass index, require insulin therapy for glycemic control, have insulin resistance, and do not develop ketosis on insulin withdrawal [56]. Interestingly, the clinical picture of MMDM is similar to that of type $1 \mathrm{DM}$, but it develops upon a background of chronic malnutrition in childhood [57]. Thus, absence of ketonuria and ketosis despite very severe hyperglycemia in lean young patients is the most significant marker of MMDM [56]. In 1999, the WHO- revised classification of diabetes based on the etiopathogenesis of the disease identifies only two categories- type $1 \mathrm{DM}$ and type $2 \mathrm{DM}$ [56]. Basically, type $1 \mathrm{DM}$ is a polygenic disease with an auto-immune basis, and this has led to the speculation by several investigators that an auto-immune mechanism is also involved in the etiology of MMDM [58-60]. For instance, it has been observed that sub-clinical or 'silent' celiac disease is present in patients with MMDM and must be taken into consideration in the diagnosis of MMDM [59,60]. Although it appears that malnutrition may influence the expression of several types of diabetes, the evidence that diabetes can be caused by chronic malnutrition or protein deficiency per se is not convincing and remains speculative [56,61,62]. Nevertheless, another investigator [63] has conclusively documented that chronic undernutrition may also accentuate beta-cell dysfunction in type $2 \mathrm{DM}$ leading to increased glucose intolerance. Comparing undernourished and obese subjects with diabetes, it was observed that while fasting glucose and free insulin levels were similar in both groups, glucose tolerance was markedly worse in the undernourished subjects [63]. Furthermore, undernutrition is known to diminish insulin secretory reserve by reducing the beta-cell number, size and granulation [63]. Nonetheless, the 'controversies' about the link 
between chronic undernutrition and diabetes may hopefully be resolved by further research on the subject.

\section{Conclusions}

There is an established link between obesity and type $2 \mathrm{DM}$, but the causal relationship between chronic undernutrition and diabetes remains controversial. Childhood diabetes- particularly type $2 \mathrm{DM}$ is gaining global prominence probably because of the double burden of malnutrition, which is an emerging health problem in developing countries. The rising prevalence of type $2 \mathrm{DM}$ in children is an important factor influencing the future burden of the disease. In addition, the global epicenter of the diabetes epidemic is located in tropical developing countries of Asia which are undergoing rapid urbanization and nutrition transition. Children in these regions are thus faced with a health-related dilemma. There is an urgent need to develop a comprehensive prevention program targeted at reducing diabetes risk and promoting proper nutrition among children in lowincome developing countries.

\section{References}

1. Shrimpton, Roger, Rokx, Claudia (2012) The double burden of malnutrition: a review of global evidence. Health, Nutrition and Population (HNP) discussion paper. World Bank, Washington DC.

2. Popkin BM (1994) The nutrition transition in low-income countries: an emerging crisis. Nutr Rev 52: 285-298.

3. Hu FB (2011) Globalization of diabetes: the role of diet, lifestyle, and genes. Diabetes Care 34: 1249-1257.

4. James WP, Coore HG (1970) Persistent impairment of insulin secretion and glucose tolerance after malnutrition. Am J Clin Nutr 23: 386-389.

5. Becker DJ, Pimstone BL, Hansen JD, MacHutchon B, Drysdale A (1972) Patterns of insulin response to glucose in protein-calorie malnutrition. Am J Clin Nutr 25: 499-505.

6. Chattopadhyay PS, Gupta SK, Chattopadhyay R, Kundu PK, Chakrabort R (1995) Malnutrition-related diabetes mellitus (MRDM), not diabetesrelated malnutrition. A report on genuine MRDM. Diabetes Care 18: 276-277.

7. World Health Organization (1985) Diabetes Mellitus: Report of a WHO Study Group, World Health Org, Geneva.

8. International Diabetes Federation. IDF Diabetes Atlas. Epidemiology and Morbidity. In: International Diabetes Federation.

9. Chan JC, Malik V, Jia W, Kadowaki T, Yajnik CS, et al. (2009) Diabetes in Asia: epidemiology, risk factors, and pathophysiology. JAMA 301: 2129-2140.

10. Fagot-Campagna A, Pettitt DJ, Engelgau MM, Burrows NR, Geiss LS, et al. (2000) Type 2 diabetes among North American children and adolescents: an epidemiologic review and a public health perspective. J Pediatr 136: 664-672.

11. (2000) Type 2 diabetes in children and adolescents. American Diabetes Association. Pediatrics 105: 671-680.

12. Kitagawa T, Owada M, Urakami T, Yamauchi K (1998) Increased incidence of non-insulin dependent diabetes mellitus among Japanese schoolchildren correlates with an increased intake of animal protein and fat. Clin Pediatr (Phila) 37: 111-115.

13. Ramachandran A, Snehalatha C, Satyavani K, Sivasankari S, Vijay V (2003) Type 2 diabetes in Asian-Indian urban children. Diabetes Care 26: 1022-1025.

14. Braun B, Zimmermann MB, Kretchmer N, Spargo RM, Smith RM, et al. (1996) Risk factors for diabetes and cardiovascular disease in young Australian aborigines. A 5-year follow-up study. Diabetes Care 19: 472-479.

15. Drake AJ, Smith A, Betts PR, Crowne EC, Shield JP (2002) Type 2 diabetes in obese white children. Arch Dis Child 86: 207-208.
16. Alberti G, Zimmet P, Shaw J, Bloomgarden Z, Kaufman F, et al. (2004) Type 2 diabetes in the young: the evolving epidemic: the international diabetes federation consensus workshop. Diabetes Care 27: 1798-1811.

17. Zimmet P, Alberti KG, Shaw J (2001) Global and societal implications of the diabetes epidemic. Nature 414: 782-787.

18. Narayan Venkat KM, Zhang P, Kanaya AM, Williams DE, Engelgau MM, et al. (2006) Diabetes: The pandemic and potential solutions. In: Jamison DT, Breman JG, Measham AR, et al., (Eds): Disease control priorities in developing countries. 2nd edition. Washington (DC): World Bank; chapter 30 .

19. Mokdad AH, Serdula MK, Dietz WH, Bowman BA, Marks JS, et al. (1999). The spread of the obesity epidemic in the United States, 1991-1998. JAMA 282: 1519-1522.

20. American Diabetes Association (2014) Diagnosis and classification of diabetes mellitus. Diabetes Care 37: S80-90.

21. Ciccone MM, Scicchitano P, Cameli M, Cerene A, Cortese F, et al. (2014) Endothelial function in pre-diabetes, diabetes and diabetic cardiomyopathy: a review. J Diabetes Metab 5: 364.

22. Shah AS, Gao Z, Urbina EM, Kimball TR, Dolan LM (2014) Pre-diabetes: the effects on arterial thickness and stiffness in obese youth. J Clin Endocrinol Metab 99: 1037-1043.

23. Tian L, Zhu J, Liu L, Liang Y, Li J, et al. (2014) Pre-diabetes and shortterm outcomes in non-diabetic patients after acute ST elevation myocardial infarction. Cardiology 127: 56-61.

24. Erdogan D, Yucel H, Uysal BA, Ersoy IH, Icli A, et al. (2013). Effects of prediabetes and diabetes on left ventricular and coronary micro vascular functions. Metabolism 62:1123-1130.

25. Levitan EB, Song Y, Ford ES, Liu S (2004). Is non-diabetic hyperglycemia a risk factor for cardiovascular disease? A meta-analysis of prospective studies. Arch Intern Med 164:2147-2155.

26. Balletshoter BM, Rittig K, Enderle MD, Volk A, Maerker E, et al (2000). Endothelial dysfunction is detectable in young normotensive first degree relatives of subjects with type 2 diabetes in association with insulin resistance. Circulation 101:1780-1784.

27. Goldtine AB, Beckman JA, Betensky RA, Derlin H, Hurley S, et al (2006). Family history of diabetes is a major determinant of endothelial function. J Am Coll Cardiol 47:2456-2461.

28. Scuteri A, Tesauro M, Rizza S, Jantomo M, Federici M, et al. (2008) Endothelial function and arterial stiffness in normotensive normoglycemic first degree relatives of diabetic patients are independent of the metabolic syndrome. Nutr Metab Cardiovasc Dis 18:349-456.

29. Hopkins KD, Lehmann ED, Jones RL, Thray RC, Gosling RG (1996) A family history of NIDDM is associated with decreased aortic distensibility in normal healthy young adult subjects. Diabetes Care 19:501-503.

30. Lee BC, Shore AC, Humphreys JM, Lowe GD, Rumley A, et al. (2001). Skin micro vascular vasodilatory capacity in offspring of two parents with type 2 diabetes. Diabetes Med 18:541-545.

31. Pannacciulli N, De Pergola G, Ciccon M, Rizzon P, Giorgino F, et al. (2003). Effect of family history of type 2 diabetes on the intima-media thickness of common carotid artery in normal-weight, overweight and obese glucose tolerant young adults. Diabetes Care 26:1230-1234.

32. Scicchitano P, Cameli M, Maiello M, Modesti PA, Muiesan ML, et al. (2014) Nutraceuticals and dyslipidemia: Beyond the common therapeutics. J Funct Foods 6: 11-32.

33. Ciccone MM, Scicchitano P, Gesualdo M, Zito A, Carbonara S, et al. (2013) The role of omega-3 polyunsaturated fatty acids supplementation in childhood: a review. Recent Pat Cardiovasc Drug Discov 8: 42-55.

34. Golay A, Ybarra J (2005) Link between obesity and type 2 diabetes. Best Pract Res Clin Endocrinol Metab 19: 649-663.

35. Anjana M, Sandeep S, Deepa R, Vimaleswaran KS, Farooq S, et al. (2004) Visceral and central abdominal fat and anthropometry in relation to diabetes in Asian Indians. Diabetes Care 27: 2948.

36. Tillin T, Hughes AD, Godsland IF (2013) Insulin resistance and truncal obesity as important determinants of the greater incidence of diabetes in 
Citation: Uwaezuoke SN (2015) Childhood Diabetes Mellitus and the 'Double Burden of Malnutrition': An Emerging Public Health Challenge in Developing Countries. J Diabetes Metab 6: 597. doi:10.4172/2155-6156.1000597

Page 5 of 5

Indian Asians and African Caribbeans compared with Europeans: the Southall and Brent Revisited (SABRE) cohort. Diabetes Care 36:383-393.

37. Bavenholm PN, Kuhl J, Pigon J, Saha AK, Ruderman NB, et al. (2003) Insulin resistance in type 2 diabetes: association with truncal obesity, impaired fitness, and atypical malonyl co-enzyme A regulation. J Clin Endocrinol Metab 88:82-87

38. Duman BS, Turkoglu C, Gunay D, Cagatay P, Demiroglu C, et al. (2003) The inter-relationship between insulin secretion and action in type 2 diabetes mellitus with different degrees of obesity: evidence supporting central obesity. Diabetes Butr Metab 16: 243-250.

39. Poehlman ET (1998) Abdominal obesity: the metabolic multi-risk factor. Coronary Herat Disease Exp 9: 469-471.

40. Morkedal B, Romundstad PR, Vatten LJ (2011) Informativeness of indices of blood pressure, obesity and serum lipids in relation to ischaemic heart disease mortality: the HUNT-II Study. Eur J Epidemiol 26: 457-461.

41. Degawa-Yamauchi MBJE, Juliar BE, Watson W, Kerr K, et al. (2003) Serum resistin (FIZZ 3) protein is increased in obese humans. J Clin Endocrinol Metabol 88:5452-5455.

42. Vendrell J, Broch M, Vilarrasa N, Molina A, Gomez JM, et al. (2004) Resistin, adiponectin, ghrelin, leptin, and pro-inflammatory cytokines: relationships in obesity. Obesity Research 12: 962-971.

43. Silha JV, Krsek M, Skrha JV, Sucharda P, Nyomba BL, et al. (2003) Plasma resistin, adiponectin and leptin levels in lean and obese subjects: correlations with insulin resistance. Eur J Endocrinol 149: 331-335.

44. Steppan CM, Bailey ST, Bhat S, Brown EJ, Banerjee RR, et al. (2001) The hormone resistin links obesity to diabetes. Nature 409: 307-312.

45. Fujinami A, Obayashi H, Ohta K, Ichimura T, Nishimura M, et al. (2004) Enzyme-linked Immunosorbent assay for circulating human resistin: resistin concentrations in normal subjects and patients with type 2 diabetes. Clin Chim Acta 339: 57-63.

46. Pingping Li, Da Young Oh, Bandyopadhyay G, Lagakos WS, Talukdar S, et al. (2015) LTB4 promotes insulin resistance in obese mice by acting on macrophages, hepatocytes and myocytes. Nature Medicine 21: 239-247.

47. Piwoz EG, Preble EA (2000) HIV/AIDS and Nutrition: A Review of the Literature and Recommendations for Nutritional Care and Support in Sub-Saharan Africa. Washington DC: Academy for Educational Development. PN-ACK-673.

48. Zuidema PJ (1959) Cirrhosis and disseminated calcification of the pancreas in patients with malnutrition. Trop Geog Med 11: 70-74.
49. Abu-Bakare A, Taylor R, Gill GV, Alberti KG (1986) Tropical or malnutrition-related diabetes: a real syndrome? Lancet I: 1135-1138.

50. Akanji AO (1990) Malnutrition-related diabetes in young adult diabetic patients attending a Nigerian diabetic clinic. Am J Tropical Med Hygiene 93: 35-38.

51. Nwokolo C, Oli J (1980) Pathogenesis of juvenile Tropical Pancreatitis Syndrome. Lancet III: 456-459.

52. Azad-Khan AK, Banik NG, Mahtab H (1991) Malnutrition-related diabetes mellitus in Bangladesh. In Diabetes Excerpta Medica, ICS 1000, Rifkin H, Colwel JA, Taylor SI (Eds). Elsevier. Amsterdam: 944-949.

53. Tripathy BB, Samal KC (1993) Protein- deficient diabetes mellitus (PDDM) in India. Int J Diabetes Dev Countries 13: 3-13.

54. Rao RH (1984) The role of undernutrition in the pathogenesis of diabetes mellitus. Diabetes Care 7: 595-601.

55. Ahren B, Corrigan CB (1985) Intermittent need for insulin in sub-group of diabetic patients in Tanzania. Diabetic Med 2: 262-264.

56. Yessoufou A, Ategbo J, Moutairou K, Dramane KL, Khan NA (2008) Malnutrition-modulated diabetes mellitus (MMDM): a state of review. Int J Biol Chem Sci. 2: 230-238.

57. Samal KC, Kanungo A, Sanjeevi CB (2002) Clinicoepidemiological and biochemical profile of malnutrition-modulated diabetes mellitus. Ann. N. Y. Acad Sci $958: 131-137$.

58. Kanungo A, Samal KC, Sanjeevi CB (2002) Molecular mechanisms involved in the etiopathogenesis of malnutrition-modulated diabetes mellitus. Ann. N. Y. Acad Sci 958 : 138-143.

59. Deja G, Myrda A, Jarosz-Chobot P, Siekiera U (2008) The assessment of auto-immunological status and prevalence of different forms of celiac disease among children with type 1 diabetes mellitus and celiac disease. Mediators Inflamm. 28: 58-89.

60. Salardi S, Volta U, Zucchini S, Fiorini E, Maltoni G, et al. (2008) Prevalence of celiac disease in children with type 1 diabetes mellitus increased in mid-1990s: an 18-year longitudinal study based on antiendomysial antibodies. J Pediatr Gastroenterol Nutr 46: 612-614.

61. Al-Amin AN, Ahren B (1999) Relation between malnutrition and development of diabetes mellitus. Int J Pancreatol 26: 125-130.

62. Abdulkadir J (1993) Malnutrition-related diabetes mellitus in Africa. Int J Diab Dev Countries 13: 22-28.

63. Rao RH (1990) Chronic undernutrition may accentuate the beta-cell dysfunction of type 2 diabetes. Diabetes Res Clin Pract 8: 25-130. 